\title{
PENGARUH MEDIA AUDIOVISUAL TERHADAP HASIL BELAJAR BAHASA INDONESIA DALAM MATERI DONGENG PADA MURID KELAS V
}

\author{
Maulidah, Abdan Syakur. \\ Pendidikan Guru Sekolah Dasar, Fakultas Keguruan dan Ilmu Pendidikan \\ Universitas Muhammadiyah Makassar \\ Maulidhaluph@yahoo.co.id
}

\begin{abstract}
ABSTRAK
Penelitian ini bertujuan untuk untuk mengetahui pengaruh media audiovisual terhadap hasil belajar bahasa Indonesia. jenis penelitian eksperimen semu yaitu suatu penelitian dimana peneliti secara sengaja memanipulasi suatu variabel (memunculkan atau tidak memunculkan suatu variabel) kemudian memeriksa efek atau akibat yang ditimbulkannya. Desain penelitian ini menggunakan "One Group Pre test - Post test". Populasi dalam penelitian ini adalah siswa kelas V SDN 146 Bontokanang dan sampel dalam penelitian ini adalah siswa kelas 5 di SDN 146 Inpres Bontokanang, yang berjumlah 27 orang dengan jumlah laki-laki sebanyak 14 orang dan perempuan sebanyak 13 orang. Instrumen dalam penelitian ini adalah tes. Untuk menganalisis data yang diperoleh dari hasil penelitian akan digunakan analisis statistik deskriptif dan inferensial. Pelaksanaan pembelajaran Bahasa Indonesia dengan menggunakan media audiovisual dengan materi dongeng pada murid kelas V SDN 146 Inpres Bontokanang adalah rata-rata hasil belajar pre test yang diperoleh adalah sebesar 56,33 dengan persentase ketuntasan yaitu 37,04 \% yang berada pada kategori sangat rendah. Adapun rata-rata hasil belajar post test yang diperoleh adalah sebesar 77,59 dengan peresentase ketuntasan yaitu 85,19 \% yang berada pada kategori sangat tinggi. Adapun hasil akhir dari t hitung dengan menggunakan software SPSS yaitu, 7,446 dengan $\mathrm{db}=27-1=26$ berada pada taraf signifikansi 5 $\%$ dengan $t$ tabel sebesar 2,056. Oleh karena $t_{\text {hitung }}>t_{\text {tabel }}$ pada taraf signifikansi 0,05 , maka hipotesis nol $\left(\mathrm{H}_{0}\right)$ ditolak dan hipotesis alternative $\left(\mathrm{H}_{\mathrm{a}}\right)$ diterima. Berdasarkan dari data di atas, maka dapat disimpulkan bahwa "Media Audiovisual berpengaruh terhadap hasil belajar Bahasa Indonesia pada murid kelas V SDN 146 Inpres Bontokanang.
\end{abstract}

Kata kunci : Pengaruh Media Audiovisua;, dan Hasil Belajar Bahasa Indonesia 


\section{PENDAHULUAN}

Pendidikan merupakan suatu usaha sadar yang bertujuan untuk mengembangkan kualitas manusia sebagai suatu kegiatan yang sadar akan tujuan, maka dalam pelaksanaannya berada dalam suatu proses yang berkesinambungan dalam setiap jenis dan jenjang pendidikan. Proses belajar mengajar atau prosespengajaran merupakan suatu kegiatan melaksanakan kurikulum agar dapat mempengaruhi para siswa dalam mencapai tujuan pendidikan yang telah ditetapkan.

Tujuan pendidikan pada dasarnya mengantarkan para siswa menuju pada perubahan-perubahan tingkah laku baik intelektual, moral maupun sosial agar dapat hidup mandiri sebagai individu dan makhluk sosial.Lingkungan belajar yang diatur oleh guru mencakup tujuan, metodologi, dan penelitian pembelajaran. Untuk membantu guru dalam mengajar atau menyampaikan materi, maka diperlukan media pembelajaran sebagai alat bantunya. Media pembelajaran termasuk ke dalam metodologi pengajaran.

Pemilihan media harus disesuaikan dengan materi dan karakteristik siswa, karena kesalahan pemilihan media pembelajaran dapat mengakibatkan tidak tersampaikannya materi pada siswa. Media adalah perantara atau pengantar pesan dari pengirim ke penerima pesan.Langkah yang perlu diambil dalam menunjang kegiatan pembelajaran agar efektif dan efisien adalah seorang guru selain memiliki kemampuan dalam mengembangkan metode pembelajaran juga diharapkan dapat memanfaatkan media pembelajaran yang telah disesuaikan dengan tujuan pembelajaran yang ingin dicapai. Kegiatan pembelajaran sebagai suatu system memandang bahwa media merupakan bagian penting dalam kegiatan tersebut. Dengan fungsi media yang seperti itu, kedudukan media sama pentingnya dengan komponenkomponen lain dalam sistem pembelajaran yaitu tujuan pembelajaran, materi pembelajaran, dan strategi pembelajaran. Materi pembelajaran yang akan dibahas dalam penelitian ini yakni Bahasa Indonesia, dan terdapat suatu prosedur pada saat guru memanfaatkan sebuah media yang digunakan dalam kegiatan pembelajaran pada mata pelajaran.

Bahasa Indonesia adalah bahasa yang digunakan untuk alat komunikasi 
dalam kehidupan sehari-hari, bahasa indonesia merupakan mata pelajaran yang mempelajari tentang bagaimana seseorang berkomunikasi, saling berbagi pengalaman, saling belajar dari orang lain, serta untuk meningkatkan kemampuan intelektual dan kasusastraan yang merupakan salah satu sarana untuk menuju pemahaman. Berdasarkan hal tersebut, maka pemanfaatan media memiliki arti penting dalam membantu guru untuk menjelaskan materi pada siswa, karena fungsi media adalah sebagai pengirim/pengantar pesan.

Pada mata pelajaran Bahasa Indonesia selain penguasaan materi menulis dan membaca, kemampuan bercerita merupakan suatu kompetensi yang juga harus dikuasai oleh siswa pada tingkat SD, hal ini sesuai dengan Silabus Bahasa Indonesia SD.

Berdasarkan uraian di atas rumusan masalah dalam penelitian ini adalah "Apakah Ada Pengaruh Media Audiovisual Terhadap Hasil Belajar Bahasa Indonesia Dalam Materi Dongeng Pada Murid Kelas V SDN 146 Bontokanang?. Tujuan penelitian ini adalah untuk mengetahui Apakah Ada Pengaruh Media Audiovisual Terhadap Hasil Belajar Bahasa Indonesia Dalam
Materi Dongeng Pada Murid Kelas V SDN 146 Bontokanang.

\section{METODE PENELITIAN}

Penelitian ini termasuk ke dalam jenis penelitian eksperimen semu yaitu suatu penelitian dimana peneliti secara sengaja memanipulasi suatu variabel (memunculkan atau tidak memunculkan suatu variabel) kemudian memeriksa efek atau akibat yang ditimbulkannya. Desain penelitian ini menggunakan "One Group Pre test - Post test", di mana desain penelitian ini digunakan untuk mengetahui hasil belajar siswa sebelum menggunakan media dan kemampuan siswa setelah pembelajaran menggunakan media. Dimana pembelajaran diukur sebelum dan sesudah pemberian perlakuan.

Populasi dalam penelitian ini adalah siswa kelas V SDN 146 Bontokanang dan sampel dalam penelitian ini adalah siswa kelas 5 di SDN 146 Inpres Bontokanang, yang berjumlah 27 orang dengan jumlah lakilaki sebanyak 14 orang dan perempuan sebanyak 13 orang. Instrumen dalam penelitian ini adalah tes berbentuk soal pertanyaan yang digunakan untuk pengukur pencapaian siswa setelah proses pembelajaran yang dilakukan akhir tindakan pada kelas eksperimen. 
Untuk menganalisis data yang diperoleh dari hasil penelitian akan digunakan analisis statistik deskriptif dan inferensial.

\section{HASIL PENELITIAN DAN PEMBAHASAN}

Adapun tahap awal yang dilakukan dalam penelitian ini adalah memberikan tes awal (pre test) kepada murid, tes tersebut terdiri dari 5 butir soal dalam bentuk essay. Tes awal diberikan untuk mengetahui hasil belajar murid pada mata pelajaran Bahasa Indonesia sebelum diberikan perlakuan atau treatment berupa media audivisual dalam bentuk video.

Setelah murid diberikan pretest, maka diperoleh data berupa nilai-nilai hasil tes murid. Kemudian nilai-nilai tersebut diolah dengan menggunakan software SPSS 18, dengan demikian diperoleh data statistik deskriptif sebagai berikut.

Tabel 1 Statistik Skor Hasil Belajar Murid Kelas V SDN 146 Inpres Bontokanang

\begin{tabular}{|c|c|}
\hline Statistik & Nilai Statistik \\
\hline Jumlah murid & 27 \\
\hline Nilai ideal & 100 \\
\hline Nilai maksimum & 90 \\
\hline Nilai minimum & 10 \\
\hline
\end{tabular}

\begin{tabular}{|c|c|}
\hline Rentang nilai & 80 \\
\hline Nilai rata-rata & $\mathbf{5 6 , 3 3}$ \\
\hline
\end{tabular}

Sumber : Sudjana,Nana. 2005.

Penilaian Hasil Proses Belajar

Mengajar

Berdasarkan statistik di atas, di peroleh Hasil Belajar Murid Kelas V SDN 146 Inpres Bontokanang setelah murid di berikan pretest.Data-data nilai yang di dapat dengan jumlah murid 27, nilai ideal 100, nilai maksimum 90, nilai minimum 10, rentang nilai 80 dan nilai rata-rata 56,33. Hal ini menunujukkan bahwa hasil belajar rendah.

1) Tingkat penguasaan materi Apabila skor hasil belajar murid dikelompokkan kedalam 5 kategori maka diperoleh distribusi frekuensi nilai seperti yang disajikan pada tabel 4.2 berikut.

Tabel 2. Tingkat Penguasaan Materi Pretest

\begin{tabular}{|c|c|c|c|c|}
\hline No & Interval & Frekuensi & $\begin{array}{l}\text { Perse } \\
\text { ntase } \\
(\%)\end{array}$ & $\begin{array}{l}\text { Kategori } \\
\text { Hasil } \\
\text { Belajar }\end{array}$ \\
\hline & & & & Sangat \\
\hline 1 & $0-45$ & 8 & 29,63 & Rendah \\
\hline 2 & $46-54$ & 3 & 11,11 & Rendah \\
\hline 3 & $55-69$ & 6 & 22,22 & Sedang \\
\hline 4 & $70-84$ & 8 & 29,63 & Tinggi \\
\hline 5 & $\begin{array}{l}85- \\
100\end{array}$ & 2 & 7,41 & $\begin{array}{c}\text { Sangat } \\
\text { tinggi }\end{array}$ \\
\hline & Jumlah & 27 & 100 & \\
\hline
\end{tabular}


Sumber : Sudjana,Nana. 2005. Penilaian Hasil Proses Belajar Mengajar

Berdasarkan data yang dapat dilihat pada tabel di atas maka dapat disimpulkan bahwa hasil belajar murid pada tahap pretest dengan menggunakan instrumen test dikategorikan sangat rendah yaitu 29,63 $\%$, rendah $11,11 \%$, sedang rendah $22,22 \%$, tinggi $29,63 \%$ dan sangat tingggi berada pada presentase 7,41\%. Melihat dari hasil presentase yang ada dapat dikatakan bahwa tingkat kemampuan murid dalam memahami serta penguasaan materi pelajaran Bahasa Indonesia sebelum diterapkan media audiovisual tergolong sangat rendah.

\section{Tabel 3 Deskripsi Ketuntasan Hasil}

\section{Belajar Bahasa Indonesia}

\begin{tabular}{|l|c|c|c|}
\hline Skor & Kategorisasi & Frekuensi & $\%$ \\
\hline $\begin{array}{l}0 \leq x< \\
70\end{array}$ & $\begin{array}{c}\text { Tidak } \\
\text { tuntas }\end{array}$ & 17 & 62,96 \\
\hline $\begin{array}{l}70 \leq \times \\
\leq 100\end{array}$ & Tuntas & 10 & 37,04 \\
\hline \multicolumn{2}{|c|}{ Jumlah } & 27 & 100 \\
\hline
\end{tabular}

Sumber : Sudjana,Nana. 2005. Penilaian Hasil Proses Belajar Mengajar Apabila Tabel 4.3 dikaitkan dengan indikator kriteria ketuntasan hasil belajar murid yang ditentukan oleh peneliti yaitu jika jumlah murid yang mencapai atau melebihi nilai KKM (70) $\geq 75 \%$, sehingga dapat disimpulkan bahwa hasil belajar Bahasa Indonesia murid Kelas V SDN 146 Inpres Bontokanang belum memenuhi kriteria ketuntasan hasil belajar secara klasikal dimana murid yang tuntas hanya 37,04 $\% \leq 75 \%$.

\section{Deskripsi Hasil Post-test}

Setelah murid diberikan pre test dan peneliti memperoleh data berupa nilai dari hasil pre test murid tersebut, maka tahap selanjutnya adalah memberikan perlakuan atau treatment kepada murid. Dalam tahap ini, peneliti mengajar sebanyak 3 kali pertemuan dengan menggunakan media audiovisual dalam bentuk video di dalam kelas. Selama menggunakan media audiovisual, peneliti meminta murid untuk memperhatikan video yang sedang di putar kemudian memncatat apa cerita yang di ceritakan dalam video kemudian mencari apa pesan moralnya. Hal ini menuntut murid untuk berpikir lebih ilmiah.

Setelah menggunakan media audiovisual selama 3 kali pertemuan. Tahap selanjutnya adalah memberikan tes akhir (post test) kepada murid. Tes yang diberikan berupa soal essay yang terdiri dari 5 nomor dengan soal yang sama dengan pre test. Tes akhir 
diberikan untuk mengetahui apakah nilai murid meningkat sebelum dan sesudah digunakannya media audiovisual dalam bentuk video ini.

Dengan demikian, dapat diketahui bahwa selama penelitian berlangsung terjadi perubahan terhadap kelas setelah diberikan perlakuan. Perubahan tersebut berupa nilai hasil belajar yang datanya diperoleh setelah diberikan Post- test. Perubahan tersebut dapat dilihat dari data hasil analisis statistik deskriptif yang diolah dengan software SPSS 18 berikut ini.

\section{Uji Hipotesis}

1) Nilai rata-rata

Adapun deskripsi secara kuantitatif skor hasil belajar Post-test setelah diberikan perlakuan (treatment), yaitu dapat dilihat pada tabel 4.4 berikut.

Tabel 4 Statistik Skor Hasil Belajar Murid Kelas V SDN 146 I npres Bontokanang

\begin{tabular}{|c|c|}
\hline Statistik & $\begin{array}{c}\text { Nilai } \\
\text { Statistik }\end{array}$ \\
\hline Jumlah murid & 27 \\
Nilai ideal & 100 \\
Nilai maksimum & 100 \\
Nilai minimum & 45 \\
Rentang nilai & 55 \\
Nilai rata-rata & $\mathbf{7 7 , 5 9}$ \\
\hline
\end{tabular}

Sumber : Sudjana,Nana. 2005. Penilaian Hasil Proses Belajar Mengajar

Berdasarkan statistik di atas, di peroleh Hasil Belajar Murid Kelas V SDN 146 Inpres Bontokanang setelah murid di berikan pretest.Data-data nilai yang di dapat dengan jumlah murid 27, nilai ideal 100 , nilai maksimum 100, nilai minimum 45, rentang nilai 55 dan nilai rata-rata 77,59 . Hal ini menunujukkan bahwa hasil belajar tinggi.

2) Tingkat penguasaan materi

Apabila skor hasil belajar murid dikelompokkan kedalam 5 kategori maka diperoleh distribusi frekuensi nilai seperti yang disajikan pada tabel 4.2 berikut.

Tabel 5. Tingkat Penguasaan Materi Post-test

\begin{tabular}{|l|l|l|l|l|}
\hline No. & interval & frekuensi & $\begin{array}{l}\text { Persen } \\
\text { tase }\end{array}$ & $\begin{array}{l}\text { Kategori } \\
\text { Hasil } \\
\text { Belajar }\end{array}$ \\
\hline 1. & $0-45$ & 1 & 3,70 & $\begin{array}{l}\text { Sangat } \\
\text { rendah }\end{array}$ \\
\hline 2. & $45-54$ & 1 & 3,70 & Rendah \\
3. & $55-69$ & 2 & 7,41 & Sedang \\
\hline 4. & $70-84$ & 12 & 44,44 & Tinggi \\
\hline 5. & $85-100$ & 11 & 40,74 & $\begin{array}{l}\text { Sangat } \\
\text { tinggi }\end{array}$ \\
\hline \multicolumn{2}{|l|}{ Jumlah } & 27 & 100 & \\
\hline
\end{tabular}

Sumber : Sudjana,Nana. 2005. Penilaian

Hasil Proses Belajar Mengajar

Berdasarkan data yang dapat dilihat pada tabel di atas maka dapat 
disimpulkan bahwa hasil belajar murid pada tahap post-test dengan menggunakan instrumrn test dikategorikan sangat tinggi yaitu 40,74 $\%$, tinggi $44,44 \%$, sedang $7,41 \%$, rendah $3,70 \%$, dan sangat rendah berada pada presentase 3,70 \%. Melihat dari hasil presentase yang ada dapat dikatakan bahwa tingkat kemampuan murid dalam memahami serta penguasaan materi pelajaran Bahasa Indonesia setelah diterapkan media audiovisual tergolong tinggi.

Tabel 6 Deskripsi Ketuntasan Hasil Belajar Bahasa Indonesia

\begin{tabular}{|l|l|l|l|}
\hline & $\begin{array}{l}\text { Katego } \\
\text { risasi }\end{array}$ & Frekuensi & $\%$ \\
\hline $\begin{array}{l}0 \leq \times \\
<70\end{array}$ & tuntas & 4 & $\begin{array}{l}14,81 \\
\%\end{array}$ \\
\hline $\begin{array}{l}70 \leq \\
\times \leq \\
100\end{array}$ & 23 & $\begin{array}{l}85,19 \\
\%\end{array}$ \\
\hline Jumlah & 27 & 100 \\
\hline
\end{tabular}

Sumber : Sudjana,Nana. 2005

Penilaian Hasil Proses Belajar Mengajar

Apabila Tabel 4.6 dikaitkan dengan indikator kriteria ketuntasan hasil belajar murid yang ditentukan oleh peneliti yaitu jika jumlah murid yang mencapai atau melebihi nilai KKM (70) $\geq 75 \%$, sehingga dapat disimpulkan bahwa hasil belajar
Bahasa Indonesia murid Kelas V SDN 146 Inpres Bontokanang telah memenuhi kriteria ketuntasan hasil belajar secara klasikal dimana murid yang tuntas adalah $85,19 \%$. $\leq 75 \%$.

2. Analisis Data statistik Inferensial Pengujian data statistik inferensial dalam penelitian ini diolah menggunakan software SPSS jenis sampel berpasangan atau sampel berhubungan (Paired Sample $t$ Test). Adapun hasil akhir dari t hitung dengan menggunakan software SPSS yaitu, 7,446 dengan $\mathrm{db}=27-1=26$ berada pada taraf signifikansi $5 \%$ dengan $\mathrm{t}$ tabel sebesar 2,056.

Berdasarkan hasil pree-test, nilai rata-rata hasil belajar murid 56,33 dengan kategori yakni sangat rendah yaitu $29,63 \%$, rendah $11,11 \%$, sedang $22,22 \%$, tinggi $29,63 \%$ dan sangat tingggi berada pada presentase 7,41\%.. Melihat dari hasil presentase yang ada dapat dikatakan bahwa tingkat kemampuan murid dalam memahami serta penguasaan materi pelajaran Bahasa Indonesia sebelum menggunakan media audiovisual tergolong sangat rendah.

Selanjutnya nilai rata-rata hasil post-test adalah 77,59. Jadi hasil belajar IPS setelah digunakan atau di terapkannya media audiovisual 
mempunyai hasil belajar yang lebih baik dibanding dengan sebelum penggunaan media audiovisual dalam bentuk video ini. Selain itu persentasi kategori hasil belajar Bahasa Indonesia murid juga meningkat yakni sangat tinggi yaitu $40,74 \%$, tinggi $44,44 \%$, sedang 7,41 \%, rendah $3,70 \%$, dan sangat rendah berada pada presentase 3,70 \%.

Berdasarkan hasil analisis statistik inferensial dengan menggunakan software SPSS, dapat diketahui bahwa nilai thitung sebesar 7,446. Dengan frekuensi (dk) sebesar 27 - $1=26$, pada taraf signifikansi $5 \%$ diperoleh $t_{\text {tabel }}=2,056$. Oleh karena $t_{\text {hitung }}>t_{\text {tabel }}$ pada taraf signifikansi 0,05 , maka hipotesis nol $\left(\mathrm{H}_{0}\right)$ ditolak dan hipotesis alternative $\left(\mathrm{H}_{\mathrm{a}}\right)$ diterima yang berarti bahwa penggunaan media audiovisual mempengaruhi hasil belajar siswa.

\begin{tabular}{l}
\multicolumn{2}{c}{ Berdasarkan hasil analisis } \\
statistik deskriptif dan \\
inferensial yang diperoleh, dapat \\
disimpulkan $\quad$ bahwa dengan
\end{tabular}
menggunakan media audiovisual siswa mampu mnceritakan kembali apa yang mereka lihat,mampu menyebutkan tokoh-tokoh dalam cerita dan menemukan pesan moral atau amanat dalam cerita,hal ini membuktikan bahwa dengan penggunaan media auidiovisual memiliki pengaruh terhadap hasil belajar Bahasa Indonesia pada murid kelas V SDN 146 Inpres Bontokanang

\section{KESIMPULAN}

Simpulan yang lebih rinci berkaitan pelaksanaan pembelajaran Bahasa Indonesia dengan menggunakan media audiovisual dengan materi dongeng pada murid kelas V SDN 146 Inpres Bontokanang adalah rata-rata hasil belajar pre test yang diperoleh adalah sebesar 56,33 dengan persentase ketuntasan yaitu 37,04 \% yang berada pada kategori sangat rendah. Adapun rata-rata hasil belajar post test yang diperoleh adalah sebesar 77,59 dengan peresentase ketuntasan yaitu 85,19 \% yang berada pada kategori sangat tinggi. Adapun hasil akhir dari t hitung dengan menggunakan software SPSS yaitu, 7,446 dengan $\mathrm{db}=27-1=26$ berada pada taraf signifikansi $5 \%$ dengan $\mathrm{t}$ tabel sebesar 2,056. Oleh karena $t_{\text {hitung }}>$ $t_{\text {tabel }}$ pada taraf signifikansi 0,05 , maka hipotesis nol $\left(\mathrm{H}_{0}\right)$ ditolak dan hipotesis alternative $\left(\mathrm{H}_{\mathrm{a}}\right)$ diterima. Berdasarkan dari data di atas, maka dapat disimpulkan bahwa "Media Audiovisual berpengaruh terhadap hasil belajar Bahasa Indonesia pada murid kelas $\mathrm{V}$ SDN 146 Inpres Bontokanang. 


\section{DAFTAR PUSTAKA}

Arikunto. 2010. Prosedur Penelitian (Satuan Pendekatan Praktik). Jakarta: Rineka Cipta.

Aunurrahman. 2012. Belajar Dan Pembelajaran. Bandung: Alfabeta.

Deway, John. 1916. Democracy an Education. Jakarta : Alfabeta. Dimyati, Mudjiono. 1999. Belajar dan Pembelajaran. Jakarta : Rineka Cipta.

Djumingin, Sulastriningsih .2011. Model Pembelajaran Inovatif Bahasa dan Sastra.Makassar: Universitas Negeri Makassar.

Ibrahim.M.,dkk. 2000. Pembelajaran Kooperatif. Surabaya : UNESA.

Iskandarwassid dan H. Sunender, D. 2008. Srategi Pembelajaran Bahasa. Bandung: PT Remaja Rosdakarya.

Mulyatiningsih, Endang. 2013. Metode Penelitian Terapan Bidang Pendidikan. Bandung: Alfabeta.

Nurhadi. Dkk. 2003. Pembelajaran Konstektual (Contextual Teaching and Learning dan penerapan dalam KBK. Malang: Universitas Negeri Malang

Slavin,R.E.2008.Cooperative Leraning. Bandung: Nusamedia.

Santosa, Puji. Materi dan Pembelajaran Bahasa Indonesia SD. Jakarta: Universitas Terbuka. 2004.

Sugiyono. 2014. Metode Penelitian Pendidikan. Bandung: Alfabeta.
Syamsuri, Andi Sukri. dkk. 2012. Pedoman Penulisan Skripsi. Makassar. Panitia Press Unismuh Makassar.

Trianto.2009. Desain Model PembelajaranI novatif-Progresif. Jakarta: Kencana

Yania,Risdiawati.2012.Implementasi ModelPembelajaran Kooperatif Tipe Student Teams Achievement Divisions (STAD) untuk Meningkatkan Motivasi dan Hasil Belajar Akuntansi Siswa Kelas XI IPS 4 SMA Negeri 1 Imogiri Tahun Ajaran 2011/2012. Skripsi. Universitas Negeri Yogyakarta. 